\title{
BokSmart - implementing a National Rugby Safety Programme
}

W Viljoen, ${ }^{1} \mathrm{~J}$ Patricios $^{2}$

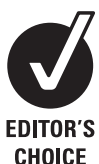

The BokSmart National Rugby Safety Programme is a joint initiative between the South African Rugby Union and the Chris Burger/Petro Jackson Players Fund aimed at implementing evidence-based sports medicine and exercise research to prevent injury and enhance performance at all levels of rugby union in South Africa.

The BokSmart programme has four main elements:

- the BokSmart Rugby Safety Workshops, a compulsory DVD-facilitated course that all coaches and referees in SA attend on a biennial basis,

- the BokSmart Rugby Medic Programme, an entry-level rugby first aid short course aimed at training members of underprivileged rugbyplaying communities,

- the toll-free BokSmart Spineline number, which assists in the management and road transport of head-, neck- and spine-injured rugby players to the nearest appropriate medical facility, and

- the freely accessible online educational resource www.boksmart.com, which provides researched documentation and practical advice on a variety of rugby-related topics.

\section{INJURY SURVEILLANCE - \\ A KEY ELEMENT}

Head and neck trauma form a large part of the injuries associated with contact and collision sport. ${ }^{6}$ Rugby Union is a collision sport that exposes players to cervical spinal injuries, with permanent disabling injuries being the most serious and highly publicised complication. ${ }^{7}$ Part

\footnotetext{
1South African Rugby Union, Cape Town, South Africa 2Morningside Sports Medicine, Johannesburg and Section of Sports Medicine, Faculty of Health Sciences, University of Pretoria, Pretoria, South Africa

Correspondence to Dr Wayne Viljoen, South African Rugby Union, $5^{\text {th }}$ Floor, Sport Science Institute Building, Boundary Road, Newlands, 7700, Cape Town, South Africa; waynev@sarugby.co.za
}

of BokSmart's mandate is to record serious and catastrophic head, neck and spine rugby injuries in South Africa (SA), and to formulate appropriate initiatives aimed at prevention of these injuries. ${ }^{4}$

Even though spinal cord injuries in rugby union are few, there are inherent risks associated primarily with the tackle and scrum $^{6}$ that are the main contributors to spinal injuries, with scrum injuries consistently being more severe..$^{3-5710}$ Over the last 4 years in SA, these phases contributed to $78 \%$ of all serious and catastrophic head, neck and spine injuries in rugby, with the tackle and scrum contributing to $41 \%$ and $37 \%$ respectively; $55 \%$ and $74 \%$ of these injuries being permanent in nature, that is, with neurological deficit, quadriplegia or death. Considering that tackle events are more common in a match, the relative risk of catastrophic outcome in scrums is therefore considerably higher.

\section{INTERVENTION - WHAT CAN BE DONE ABOUT NECK INJURIES?}

Targeted interventions on scrum-related spinal cord injuries are effective. ${ }^{4}{ }^{7} 10$ The French Rugby Union instituted new laws for scrumming, for non-professional players, and a new medical licensing procedure for front-row players called the 'rugby passport'. . New Zealand's RugbySmart programme had similar results using a different strategy. ${ }^{70}$ It is possible that the scrum may be more amenable to education-based injury-prevention initiatives than the unstructured tackle, ruck and maul. ${ }^{10}$ RugbySmart provides evidence that educational programmes are indeed a viable option for decreasing serious spinal injuries in scrums. ${ }^{10} 12$ For this reason, BokSmart implemented an educational approach akin to that of RugbySmart, but incorporated additional elements outlined in the 4-part programme to accommodate the South African rugby landscape.

\section{CONCUSSION AND FATAL HEAD INJURY}

Another key component to address proactively is concussion, the consequences of which have seen a number of concussionrelated fatalities in South African rugby. The BokSmart philosophy is that the outcome of a properly managed concussion should never be catastrophic in nature, and proper education on preventing, identifying, managing, treating and rehabilitating a player before returning to match play forms an integral part of the programme.

BokSmart's education programme reflects the most recent International Consensus Statement on Concussion in Sport. ${ }^{13} 14$ A toll-free hotline manned by emergency medical service personnel who have received additional BokSmart training, enables coaches and referees to access appropriate emergency medical advice and treatment. The programme also developed a simple preparticipation screening tool for coaches, ${ }^{15}$ which recognises concussion and neck injury history as an important predictor of catastrophic injury. ${ }^{613}$ Each coach and referee also receives a pocket Concussion Guide, which assists in providing appropriate guidance for managing potentially concussed players on field.

\section{TURNING RESEARCH INTO PRACTICE - EFFICACY TO EFFECTIVENESS}

A major challenge is turning injury prevention research into behaviour change. If causative behaviour can be amended, injuries may be prevented. In practice, one needs to find a realistic solution combining both science and pragmatism to lead to positive behavioural change. ${ }^{8} 9$ Even the most scientifically proven, effective interventions do not necessarily guarantee compliance, or translate into success, in preventing injuries in the real-world context. ${ }^{189}$ Only proven and effective interventions that become standard practice will stand a chance of preventing these injuries. ${ }^{8}$ Many interventions do not take this into account and sometimes are simply not usable in the field. ${ }^{8}$

If one explores the current literature available, there are various models to strategically align injury-prevention initiatives. ${ }^{1289}$ In practice, your approach sometimes becomes a myriad of these, especially when the sporting landscape, as in SA, is extremely diverse with different cultures, languages, socioeconomic statuses and disparate levels of education. Planning, developing and implementing an evidence-based, effective intervention in all communities is complex.

BokSmart has used a multifaceted approach ${ }^{1610}$ incorporating as many of its rugby stakeholders as possible, and availing its content via different educational 
platforms. ${ }^{2}$ This helps ensure that the strong evidence base or interventions can be applied effectively in the 'real world'.

\section{LESSONS - WHAT WORKED?}

One of the key pillars of the programme is the educational courses modelled on the DVD-facilitated approach utilised in New Zealand. ${ }^{12}$ RugbySmart ${ }^{10} 12$ was originally modelled on van Mechelen's ${ }^{16}$ approach and built on the foundation work of earlier initiatives. ${ }^{10}$ As with RugbySmart, the BokSmart programme is focused at community level, and is implemented throughout the country. ${ }^{12}{ }^{17}$ In the first 2-and-half years, BokSmart has trained roughly 38500 coaches and referees on the rugby safety course.

On-going research into the primary problem is critical in ensuring effectiveness in one's approach, and proactively addressing the identified risk factors as they surface. ${ }^{10}$ We monitor feedback from the target audience, that the desired level of interaction is being achieved, and that the product is being well received. We regularly engage with field-related experts to ensure that the intervention strategy is fluid and modifiable. This guarantees the best possible chance of learning and transfer. Understanding the barriers and enablers to the extensive adoption and sustainability of your intervention, is a crucial component in focusing your implementation efforts. ${ }^{1}$ BokSmart recognises that programme leaders must continually consider different implementation and intervention delivery approaches. ${ }^{2}$

One method of structuring a prevention programme is using the Intervention Mapping (IM) protocol, which is made up of five steps, that is, (1) defining the programme objectives based on the extent of the problem, (2) selecting the most appropriate $\operatorname{method}(\mathrm{s})$ to change the targeted behaviour or outcome, (3) designing the intervention and selecting, testing and producing the materials, (4) developing the implementation plan and (5) evaluating the intervention's effect. ${ }^{9}$ The IM protocol is a continuous and consistent dialogue with all stakeholders involved to make sure that the intervention is acceptable and feasible from an implementation perspective. ${ }^{9}$ Hence, the BokSmart programme has stakeholder expert advisory and ground-level operational panels that play a critical role in seeking maximum effect and compliance. BokSmart regularly engages with relevant stakeholders, and partners with them around delivery developments. ${ }^{2}$ Each course builds on the previous course, and the format of these courses progressively adapts to the educational needs of the participants. This also ensures that the educational materials remain up to date and provide current evidence-based best practice information to rugby participants. ${ }^{10} 12$ To increase commitment to the programme, the content also needs to be suitable for the audience with plain language take-home messages. ${ }^{12}$

The main requirement is now to establish whether the knowledge and skills acquired by the coaches and referees are actually being translated into their practices on field. ${ }^{8}$ An expert, international research team is currently evaluating the implementation of the BokSmart programme 9 in collaboration with the University of Cape Town's Research Unit for Exercise Science and Sport Medicine.

In summary - BokSmart is an example of acknowledging a major problem, identifying risk factors, developing strategies to target the problem, implementing these initiatives and putting independent processes in place to evaluate the success of the programme. The elements of the programme demonstrate the practical implementation of an injury prevention and rugby safety programme using an evidence-based approach, yet keeping in mind the rugby landscape within a South African context in an attempt to maximise adoption and impact of the programme. The ultimate result is aimed at safer rugby, and fewer catastrophic injuries. Key to maximise compliance and uptake is ongoing research, keeping current with the injury patterns of the game, regular interaction and collaboration with all rugby stakeholders, constant education of all role players, and fluid and modifiable implementation strategies that are moulded to the needs of the times.

Competing interests None.

Provenance and peer review Not commissioned; internally peer reviewed.

Received 12 April 2012

Accepted 13 April 2012

Br J Sports Med 2012;46:692-693.

doi:10.1136/bjsports-2012-091278

\section{REFERENCES}

1. Finch CF, Donaldson A. A sports setting matrix for understanding the implementation context for community sport. Br J Sports Med 2010;44:973-8.

2. Finch CF. Getting sports injury prevention on to public health agendas - addressing the shortfalls in current information sources. Br J Sports Med 2012; 46:70-4

3. Maclean JG, Hutchison JD. Serious neck injuries in U19 rugby union players: an audit of admissions to spinal injury units in Great Britain and Ireland. Br J Sports Med 2011 (In press).

4. Hermanus FJ, Draper CE, Noakes TD. Spinal cord injuries in South African Rugby Union (1980-2007). SAMJ 2010;100:230-234.

5. Dunn RN, Van der Spuy D. Rugby and cervical spine injuries - has anything changed? A 5 -year review in the Western Cape. SAMJ 2010; 100:235-238.

6. McIntosh AS, McCrory P. Preventing head and neck injury. Br J Sports Med 2005;39:314-8.

7. Bohu Y, Julia M, Bagate C, et al. Declining incidence of catastrophic cervical spine injuries in French rugby: 1996-2006. Am J Sports Med 2009;37:319-23.

8. Verhagen $\mathbf{E}$, Finch CF. Setting our minds to implementation. Br J Sports Med 2011;45:1015-6.

9. Verhagen EA, van Mechelen W. Sport for all, injury prevention for all. $\mathrm{Br} J$ Sports Med 2010; 44:158.

10. Quarrie KL, Gianotti SM, Hopkins WG, et al. Effect of nationwide injury prevention programme on serious spinal injuries in New Zealand rugby union: ecological study. BMJ 2007;334:1150

11. Noakes TD, Draper CE. Preventing spinal cord injuries in rugby union. BMJ 2007;334:1122-3.

12. Gianotti SM, Quarrie KL, Hume PA. Evaluation of RugbySmart: a rugby union community injury prevention programme. J Sci Med Sport 2009;12:371-5.

13. McCrory P, Meeuwisse W, Johnston K, et al. Consensus statement on concussion in sport - the 3rd International conference on concussion in sport held in Zurich, November 2008. J Sci Med Sport 2009 2009;12:340-51.

14. Patricios JS, Kohler RMN, Collins RM. Sportsrelated concussion relevant to the South African rugby environment - A review. SAJSM 2010;22:88-94.

15. Patricios JS, Collins RM. BokSmart: preparticipation screening of rugby players by coaches based on internationally accepted medical standards. SAJSM 2010;22:62-65.

16. van Mechelen W, Hlobil H, Kemper HC. Incidence, severity, aetiology and prevention of sports injuries. A review of concepts. Sports Med 1992;14:82-99.

17. Posthumus M, Viljoen W. BokSmart: safe and effective techniques in rugby union. SAJSM 2008;20:64-70. 


\section{B SM BokSmart - implementing a National Rugby Safety Programme}

W Viljoen and J Patricios

Br J Sports Med 2012 46: 692-693 originally published online May 19, 2012

doi: 10.1136/bjsports-2012-091278

Updated information and services can be found at:

http://bjsm.bmj.com/content/46/10/692

These include:

References This article cites 15 articles, 7 of which you can access for free at: http://bjsm.bmj.com/content/46/10/692\#BIBL

Email alerting Receive free email alerts when new articles cite this article. Sign up in the service box at the top right corner of the online article.

Topic Articles on similar topics can be found in the following collections Collections Editor's choice (268)

\section{Notes}

To request permissions go to:

http://group.bmj.com/group/rights-licensing/permissions

To order reprints go to:

http://journals.bmj.com/cgi/reprintform

To subscribe to BMJ go to:

http://group.bmj.com/subscribe/ 